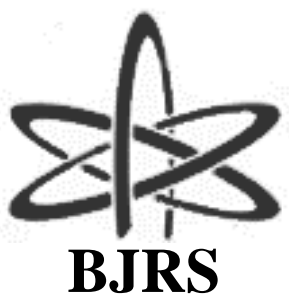

BRAZILIAN JOURNAL

$\mathrm{OF}$

RADIATION SCIENCES

07-02A (2019) 01-13

\title{
A comparison between rad-hard float zone silicon diodes as gamma dosimeter in radiation processing
}

\author{
F. Camargo ${ }^{a *}$; J. A. C. Gonçalves ${ }^{\text {b,c }}$; C. C. Bueno ${ }^{\text {b+ }}$ \\ ${ }^{a}$ Amazônia Azul Tecnologias de Defesa S.A. - AMAZUL, São Paulo/SP, Brasil \\ ${ }^{b}$ Instituto de Pesquisas Energéticas e Nucleares - IPEN-CNEN/SP, Postal Code 11049, São Paulo/SP, Brasil \\ ${ }^{c}$ Pontifícia Universidade Católica de São Paulo, Depto. Física - PUC/SP, São Paulo/SP, Brasil \\ "fdcamargo@gmail.com ; ${ }^{\dagger}$ ccbueno@ipen.br
}

\begin{abstract}
In this work, we report on the results obtained with rad-hard Standard Float Zone (STFZ) and Diffused Oxygenated Float Zone (DOFZ) silicon diodes in radiation processing dosimetry. The dosimetric probes were designed to operate in the direct current mode, as on-line radiation dosimeter. The irradiation of the samples was performed using a ${ }^{60} \mathrm{Co}$ source with a dose rate of almost $2.4 \mathrm{kGy} / \mathrm{h}$. The current response of each diode was measured as a function of the exposure time in steps from $5 \mathrm{kGy}$ up to $50 \mathrm{kGy}$ to achieve a total absorbed dose of $275 \mathrm{kGy}$. In this dose range it is observed a significant decrease in the photocurrent generated in both devices due to gamma radiation defects produced in their active volumes. To mitigate this effect, the samples were pre-irradiated with ${ }^{60} \mathrm{Co}$ gamma rays at $700 \mathrm{kGy}$. Despite of being less sensitive, these devices presented stable and reproducible current signals with a relative sensitivity decrease of about $19 \%$ within the whole range of dose studied. The dose-response curves of the pre-irradiated diodes showed quadratic behavior with correlation coefficient higher than 0.9999 for total absorbed dose up to $275 \mathrm{kGy}$. The comparison of the diodes' dosimetric responses evidenced that the best result was achieved with the DOFZ, which exhibited slightly higher sensitivity and stability than the STFZ devices. However, it is important to note that all preirradiated diodes can be used as gamma dosimeters in radiation processing applications.
\end{abstract}

Keywords: Gamma dosimetry, Silicon diode, High-dose, Float Zone diode, Rad-hard Si diode

ISSN: 2319-0612

Accept Submission 2018-12-12 


\section{INTRODUCTION}

The use of silicon diodes as on-line gamma dosimeters in radiation processing is a big challenge due to the radiation damage effects suffered by semiconductor devices, such as: sensitivity dependence on dose-rate and the decrease of sensitivity with accumulated dose, the main restriction to their application in high dose dosimetry [1]. On the other hand, semiconductor devices have been widely used for photon and electron beams dosimetry, mainly in the field of radiation protection, medical imaging and radiation therapy [1-5], where the doses are considerably lower than those delivered in some typical radiation processing applications, that can easily reach $30 \mathrm{kGy}$ or more [6].

Nevertheless, developments of rad-hard silicon diodes for high energy physics experiments have been changed this reality, allowing the use of these devices in applications under severe radiation environment [7, 8]. Among several defect engineering technologies used to decrease the radiation damage, one is to diffuse oxygen into the float zone Si bulk, increasing the oxygen concentration when compared with the standard float zone diode. This technology has shown a substantial improvement in radiation hardness, mainly when the diodes are irradiated with gamma rays [9].

In this work, we report the results of the comparison between rad-hard Diffused Oxygenated Float Zone (DOFZ) and Standard Float Zone (STFZ) silicon diodes in radiation processing dosimetry as on-line radiation dosimeter. The main advantage of recording real time currents, and consequently dose rates, is to provide continuous data of the dose delivered to the product for quality assurance in radiation processing.

\section{MATERIALS AND METHODS}

The $\mathrm{p}^{+} / \mathrm{n} / \mathrm{n}^{+}$junction devices used were produced on rad-hard float zone Si wafers of $300 \mu \mathrm{m}$ thickness, active area of $25 \mathrm{~mm}^{2}$ (surrounded by a multiple guard ring structure), resistivity about $1.4 \mathrm{k} \Omega \cdot \mathrm{cm}$ and oxygen concentration $<10^{15} \mathrm{~cm}^{-3}$. Additionally, the DOFZ wafer was passivated by oxygen diffusion into the bulk, reaching an oxygen concentration $\approx 10^{17} \mathrm{~cm}^{-3}$. Both diodes were 
manufactured by Okmetic Oyj (Finland) and processed by the Microelectronics Center of Helsinki University of Technology [10] in the framework of the CERN RD50 Collaboration. Two samples of each diode (STFZ and DOFZ) with similar characteristics related to $\mathrm{I} / \mathrm{V}$ and $\mathrm{C} / \mathrm{V}$ standard measurements, hereafter referred as STFZ\#54, STFZ\#75, DOFZ\#2 and DOFZ\#6, were used in this work. Two of them (STFZ\#54; DOFZ\#2) were not pre-irradiated, while the others (STFZ\#75; DOFZ\#6) were primed before measurements with a dose of $700 \mathrm{kGy}$. This value was previously accessed by monitoring the current sensitivity decay of similar STFZ and DOFZ diodes continuously irradiated with ${ }^{60} \mathrm{Co}$ gamma rays. The corresponding plots of radiation-induced current as a function of the accumulated dose up to $1 \mathrm{MGy}$, enabled predictions to be made about the predose needed to stabilize the current response of the diodes.

Figure 1 shows the dosimetric probe, a PolyMethilMetacrylate (PMMA) box, which protected the diodes from moisture, light and mechanic vibrations. All guard rings of the diodes were left floating, while the back plane $\left(\mathrm{n}^{+}\right)$of each device was properly grounded. The $\mathrm{p}^{+}$front electrode was directly connected, via a $2 \mathrm{~m}$ long $50 \Omega$ coaxial cable, to a Fluke 189 multimeter with time resolution of $4 \mathrm{~s}$. The photocurrents as a function of time were acquired with the FlukeView Forms ${ }^{\circledR}$ software.

Figure 1: Dosimetric probe based on the rad-hard float zone Si device.

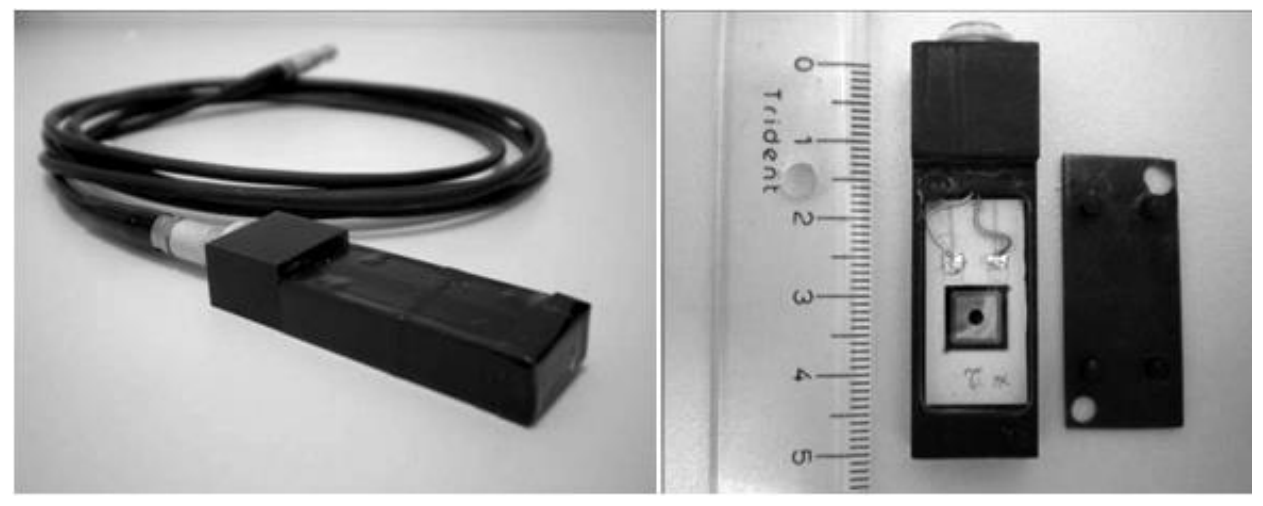

The irradiation was performed at IPEN-CNEN/SP using a 60Co source (Gammacell 220 - MDS Nordion) with traceability through the International Dose Assurance Services (IDAS) from International Atomic Energy Agency (IAEA). Figures 2a and 2b illustrates the experimental setup used to obtain the photocurrents as a function of time. 
Figure 2: (a) Schematic setup used to obtain the photocurrents as a function of time; (b)

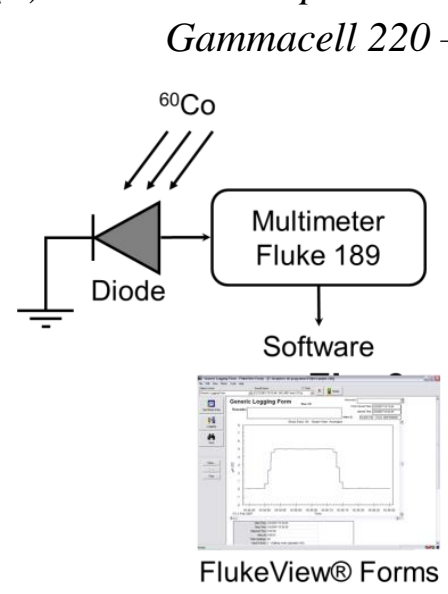

(a)

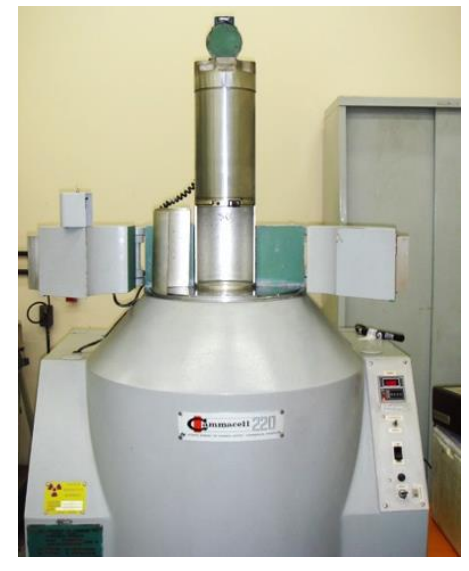

(b)

The dose rates used to irradiate each diode are listed in Table 1. The diodes were placed in the central position of the ${ }^{60} \mathrm{Co}$ irradiation chamber and irradiated in consecutive steps of $5 \mathrm{kGy}$ from $50 \mathrm{kGy}$. It took more than $110 \mathrm{~h}$ irradiation time to achieve an accumulated dose of $275 \mathrm{kGy}$ per diode. After each step, the irradiator was switched off, and the leakage current of the dosimetric probe was performed. The temperature during exposure was typically $25 \pm 3{ }^{\circ} \mathrm{C}$.

Table 1: Dose rate $(\dot{\boldsymbol{D}})$ applied by the Gammacell 220 during samples irradiation.

\begin{tabular}{ccc}
\hline Pre-Dose & Diode & $\dot{\mathbf{D}}$ (kGy/h) \\
\hline \multirow{2}{*}{ None } & DOFZ\#2 & $2.52 \pm 0.04$ \\
& STFZ\#54 & $2.33 \pm 0.04$ \\
\hline \multirow{2}{*}{$700 \mathrm{kGy}$} & DOFZ\#6 & $2.49 \pm 0.04$ \\
& STFZ\#75 & $2.31 \pm 0.04$ \\
\hline
\end{tabular}

\section{RESULTS AND DISCUSSION}

The photocurrent response of the STFZ\#54 and DOFZ\#2 diodes under ${ }^{60}$ Co gamma radiation with different exposure times is shown in Figure 3. The sensitivity dependence of the diodes on the dose 
is clearly evidenced by a fast decay of the photocurrent for accumulated doses of about $30 \mathrm{kGy}$, followed by a slower decrease at higher doses, as can be seen in the Figure 4. In order to eliminate the influence of dose rate in the generation of the photocurrent, the data in this figure are normalized by the maximum current measured at the beginning of exposition and presented as a function of the accumulated dose.

Figure 3: Current response of the (a) STFZ\#54 and (b) DOFZ\#2 diodes for successive exposure times, irradiated at the dose rate of 2.33 and $2.52 \mathrm{kGy} / \mathrm{h}$, respectively.

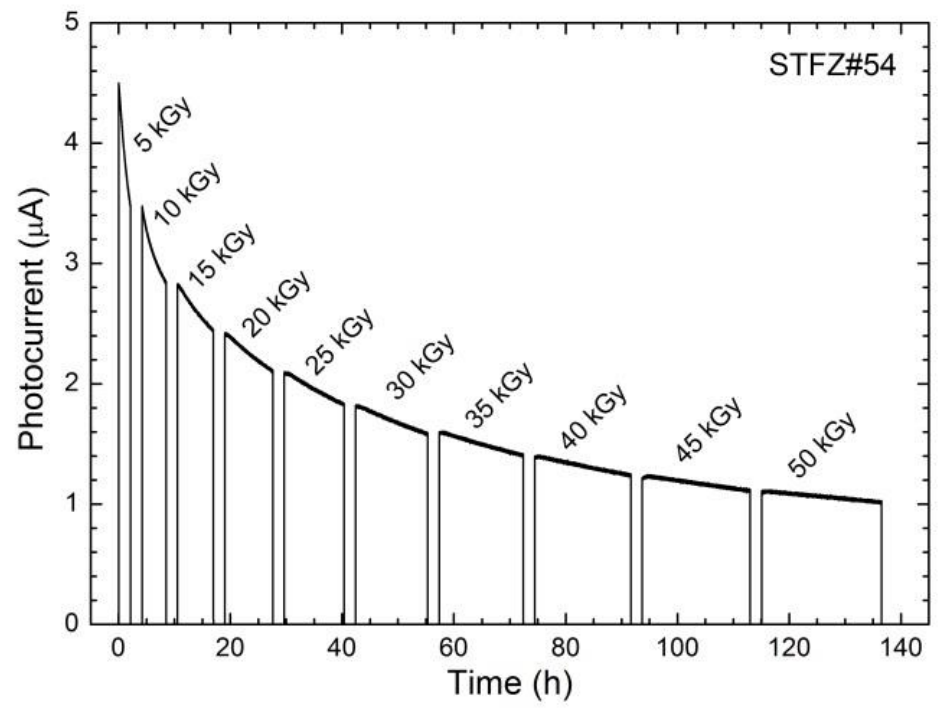

(a)

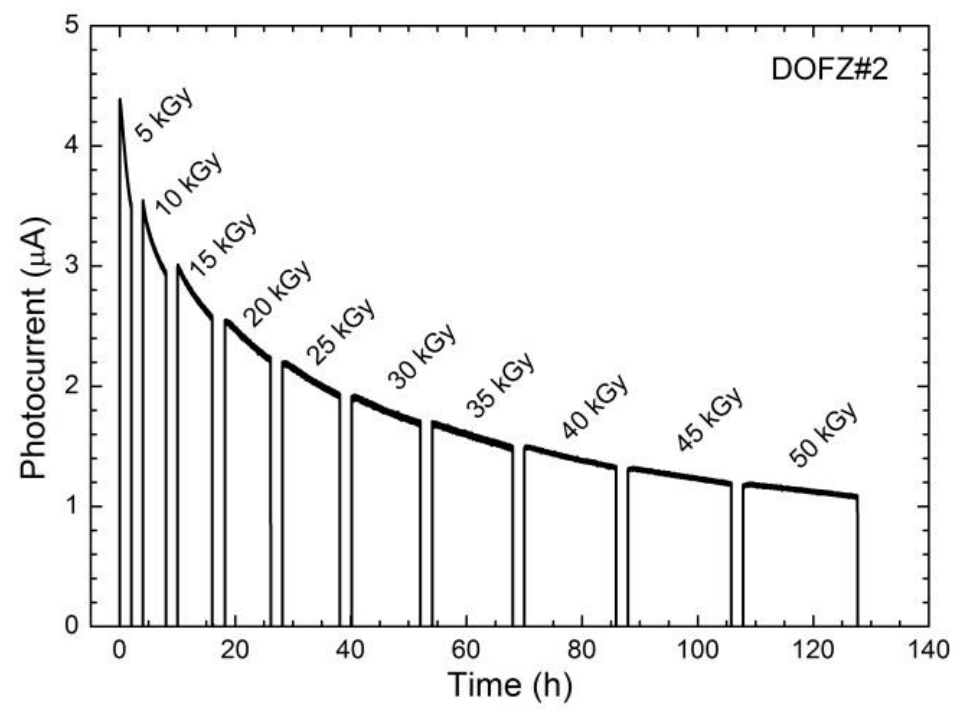

(b) 
From Figure 4, it is expected a less pronounced sensitivity decay at accumulated doses higher than approximately $300 \mathrm{kGy}$. Therefore, in order to improve the diode response stability, by reducing its sensitivity dependence on the dose, the STFZ\#75 and DOFZ\#6 samples were pre-irradiated with ${ }^{60} \mathrm{Co}$ gamma rays with a dose of about $700 \mathrm{kGy}$.

Figure 4: Normalized photocurrent for the STFZ\#54 and DOFZ\#2 diodes as a function of the accumulated dose.

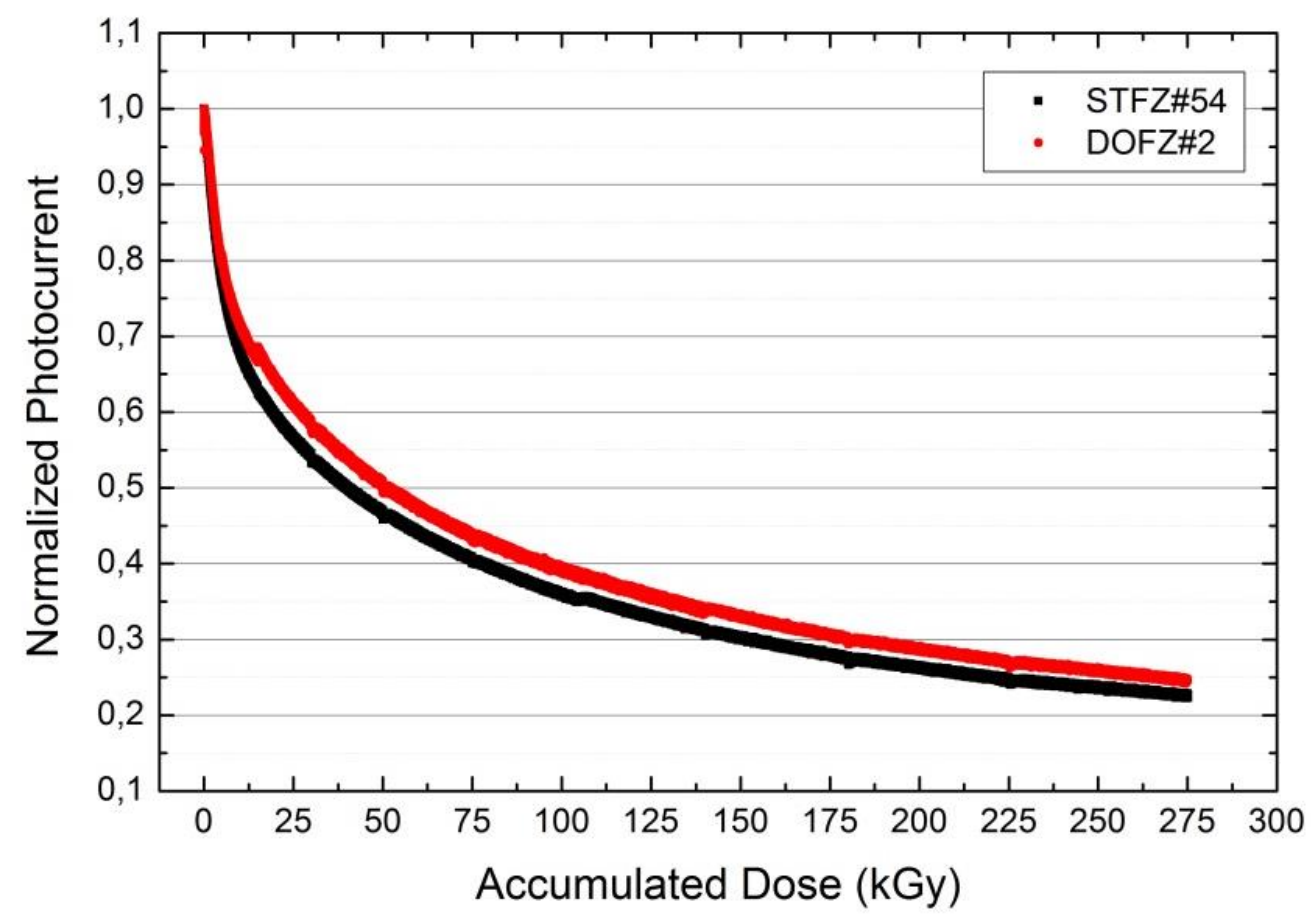

Indeed, in Figure 5, the photocurrent response of the STFZ\#75 and DOFZ\#6 diodes, evaluated for accumulated doses up to $275 \mathrm{kGy}$, presents very stable and reproducible current signals at all doses studied, as can be seen by the normalized photocurrent as a function of the accumulated dose (Figure 6). This fact can be attributed to the saturation of the traps generated in the sensitive volume of the devices by the radiation and is confirmed by the average photocurrent values and the sensitivity for the pre-irradiated devices showed in Table 2. It is important to note that, even being less sensitive after the high pre-dose, the signal to dark current ratio is about more than $10^{3}$ [11], allowing the safe use of these diodes as dosimeters. 
Figure 5: Current response of the (a) STFZ\#75 and (b) DOFZ\#6, with a pre-dose of $700 \mathrm{kGy}$, irradiated at the dose rate of 2.31 and $2.49 \mathrm{kGy} / \mathrm{h}$, respectively.

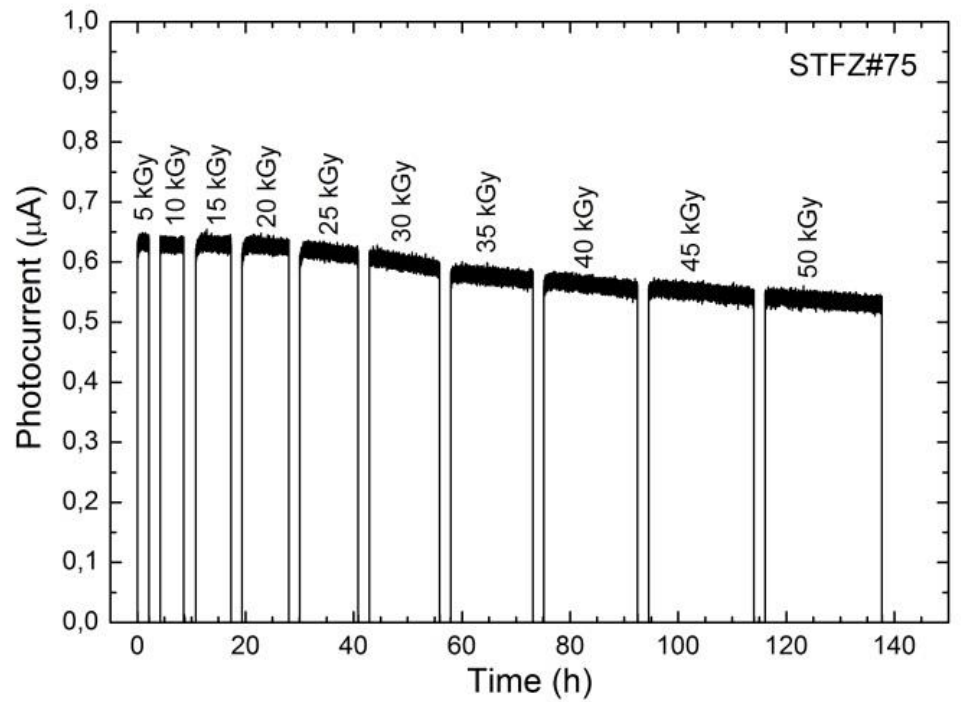

(a)

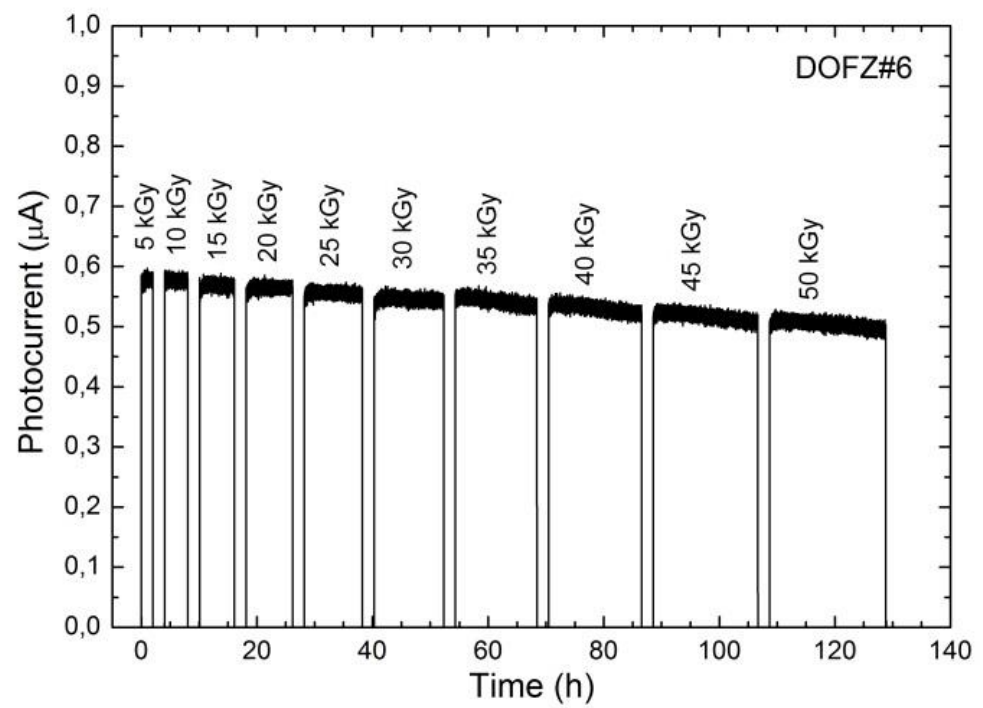

(b)

Table 2: Average photocurrent $\left(\overline{\boldsymbol{I}_{\boldsymbol{F}}}\right)$, sensitivity $(\boldsymbol{S})$ and charge sensitivity $\left(\boldsymbol{S}_{\boldsymbol{q}}\right)$ for the pre-irradiated diodes.

\begin{tabular}{ccccc}
\hline Sample & $\dot{D}(\mathrm{kGy} / \mathrm{h})$ & $\bar{I}_{F}(\mu \mathrm{A})$ & $\boldsymbol{S}(\mu \mathrm{Ah} / \mathrm{kGy})$ & $\boldsymbol{S}_{q}(\mathrm{mC} / \mathrm{kGy})$ \\
\hline STFZ\#75 & $2.31 \pm 0.04$ & $0.60 \pm 0.03$ & $0.26 \pm 0.01$ & $0.92 \pm 0.05$ \\
DOFZ\#6 & $2.49 \pm 0.04$ & $0.55 \pm 0.02$ & $0.22 \pm 0.01$ & $0.79 \pm 0.04$ \\
\hline
\end{tabular}


Analyzing the results presented in Tab. 2, it is possible to conclude that the STFZ diode is more sensitive than the DOFZ diode.

Figure 6: Normalized photocurrent for the STFZ\#54 and DOFZ\#2 diodes as a function of the accumulated dose.

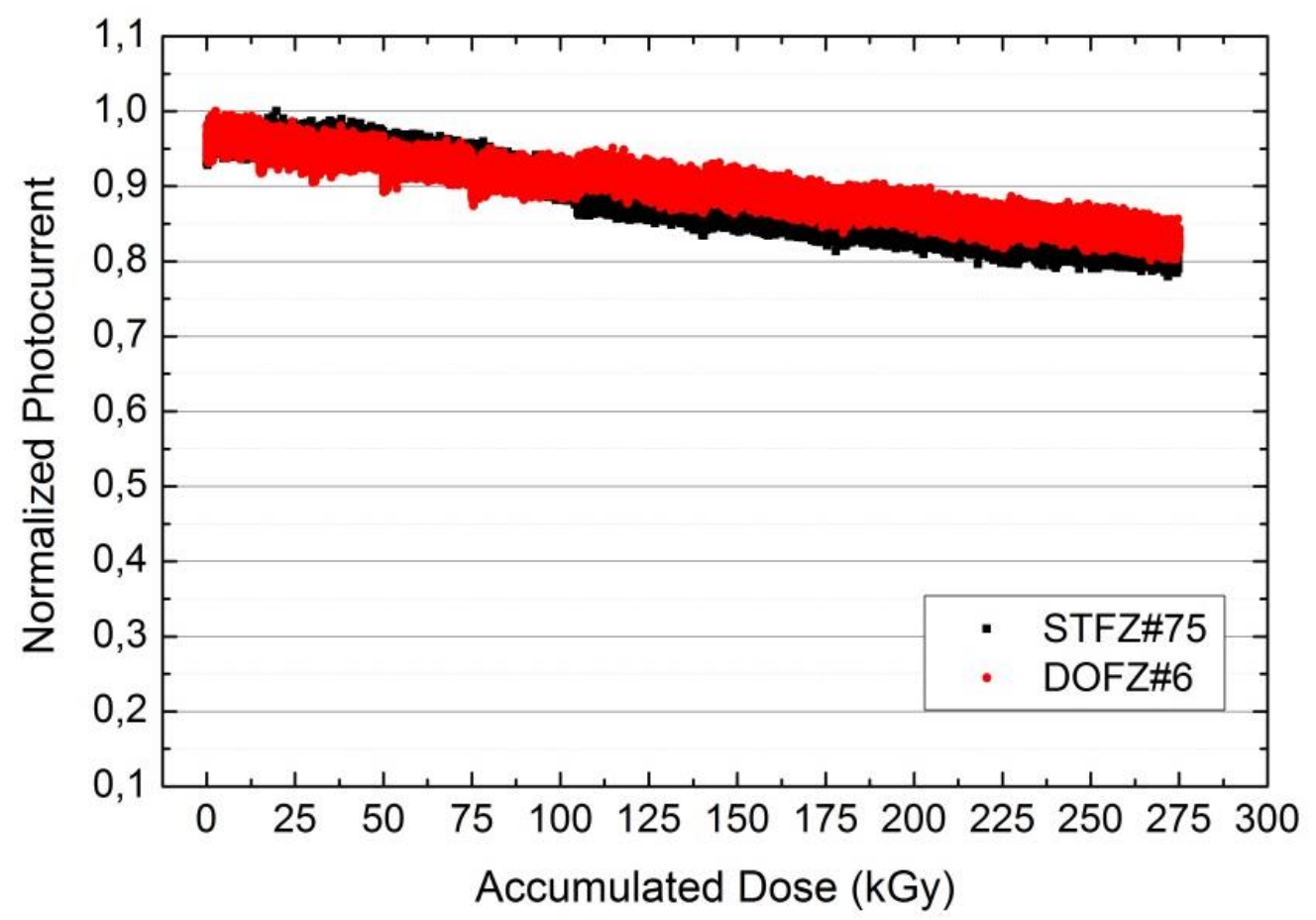

To compare the stability response of the devices, the average current signals of each exposure, normalized to the average current at $5 \mathrm{kGy}$ for each diode, are plotted in Figure 7 as a function of the accumulated dose up to $275 \mathrm{kGy}$. Within this dose range, the sensitivity decreases about $18 \%$ and $19 \%$ for the DOFZ and STFZ diodes, while for the non-irradiated diodes, for the same accumulated dose, the sensitivity in current reduced to 77\% (STFZ) and 75\% (DOFZ) respectively. 
Figure 7: Average current signals of each successive exposure, normalized to the average current at $5 \mathrm{kGy}$ of respective diode, as a function of the accumulated dose.

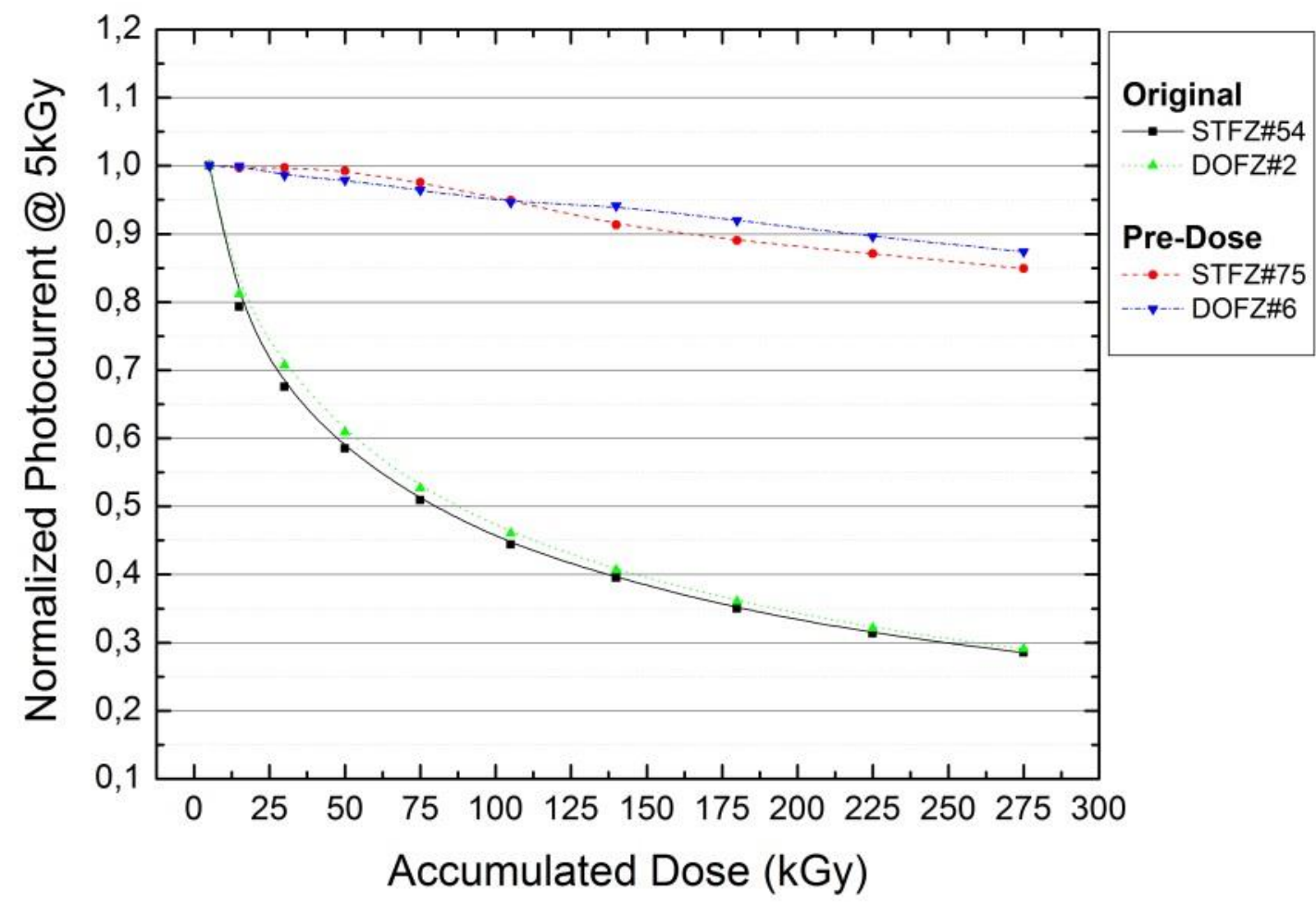

This stability is also evidenced in Figure 8 which shows the charge released in different types of devices, obtained by integrating the current signals over the exposure times, as a function of the accumulated dose. 
Figure 8: Charge as a function of the accumulated dose for diodes without (STFZ\#54 and DOFZ\#2) and with pre-dose (STFZ\#75 and DOFZ\#6).
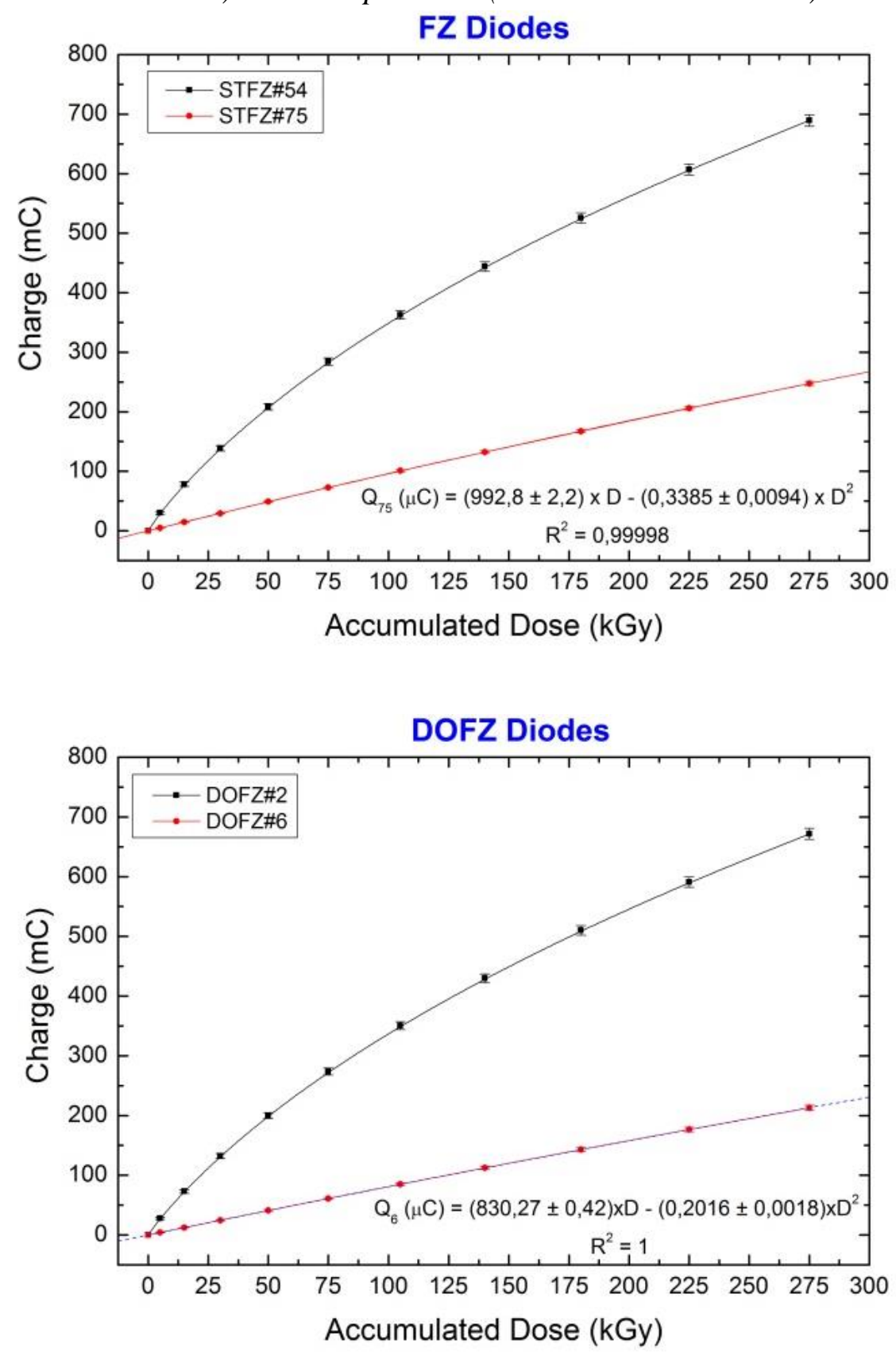

As can be seen in Figure 08, for doses higher than $30 \mathrm{kGy}$, diodes without pre-dose shown a significant saturation, probably due to point defects created in their volume by the gamma radiation. Conversely, within the whole dose range studied it was observed a quadratic response of the pre- 
irradiated diodes with a correlation coefficient $\left(\mathrm{R}^{2}\right)$ more than 0.999 . These results suggested that pre-irradiation with $700 \mathrm{kGy}$ was enough to achieve the stable response of these devices.

\section{CONCLUSION}

Rad-hard float zone diodes have been characterized as on-line ${ }^{60} \mathrm{Co}$ gamma radiation dosimeters from $5 \mathrm{kGy}$ up to $275 \mathrm{kGy}$. In this dose range, the sensitivity decrease of diodes without pre-dose (STFZ\#54 and DOFZ\#2) was about 77\%, leading to a significant saturation on their charge versus dose response. This effect, due to gamma radiation induced point-defects in the crystal bulk, was reduced by pre-irradiating the diodes (STFZ\#75 and DOFZ\#6) with a gamma ray dose of $700 \mathrm{kGy}$. Despite of being less sensitive, these devices presented stable and reproducible current signals with a relative sensitivity decrease of about only $19 \%$ within the whole range of dose studied. The calibration curves of the pre-irradiated dosimeters showed quadratic responses with correlation coefficient higher than 0.9999 for total absorbed dose up to $275 \mathrm{kGy}$. The comparison of the dosimetric response among the diodes studied evidenced that the best result was achieved with the DOFZ, which exhibited higher sensitivity and stability than the STFZ devices. However, it is important to note that all pre-irradiated diodes can be used as gamma dosimeters in radiation processing applications.

\section{ACKNOWLEDGMENT}

The authors highly acknowledge Drs. Eija Tuominen, Esa Tuovinen and Jaakko Härkönen from Helsinki Institute of Physics - HIP for the free supply of the diodes. Thanks are also addressed to Eng. Elizabeth S. R. Somessari and Eng. Carlos Gaia da Silveira, from Gammacell staff, for the collaboration during the irradiation procedures. The technical collaborations of J. P. Souza from Microelectronic Laboratory of São Paulo University and MSc M. T. Biasoli from Renato Archer Information Technology Centre are also acknowledged. 


\section{REFERENCES}

1. BARTHE, J. Electronic dosimeters based on solid state detectors. Nucl. Instr. and Meth. Section B, v. 184, p. 158-189, 2001.

2. ROSENFELD, A. B. Electronic dosimetry in radiation therapy. Radiation Measurements, v. 41, p. S134-S153, 2007.

3. CASATI, M.; BRUZZI, M.; BUCCIOLINI, M.; MENICHELlI, D.; SCARINGELLA, M.; PIEMONTE, C.; FRETWURST, E. Characterization of standard and oxygenated float zone Si diodes under radiotherapy beams. Nucl. Instr. and Meth. Section A, v. 552, pp. 158-162, 2005.

4. MENICHELli, D.; BRUZZI, M.; BUCCIOLINI, M.; TALAMONTI, C.; CASATIA, M.; MARRAZZO, L.; TESI, M.; PIEMONTE, C.; POZZA, A.; ZORZI, N.; BRIANZI, M.; DE SIO, A. Design and development of a silicon-segmented detector for $2 \mathrm{D}$ dose measurements in radiotherapy. Nucl. Instr. and Meth. Section A, v. 583, p. 109-113, 2007.

5. CAMARGO, F.; GONÇALVES, J. A. C.; KHOURY, H. J.; NAPOLITANO, C. M.; HÄRKÖNEN, J.; BUENO, C. C. MCz diode response as a high-dose gamma radiation dosimeter. Radiation Measurements, v. 43, p. 1160-1162, 2008.

6. International Atomic Energy Agency. Gamma Irradiators for Radiation Processing. IAEA Brochure, Vienna: 2005.

7. RD50 Status Report 2006. Radiation hard semiconductor devices for very high luminosity colliders. CERN-LHCC-2007-005 and LHCC-RD-013.

8. HÄRKÖNEN, J.; TUOVINEN, E.; LUUKKA, P.; NORDLUND, H. K.; TUOMINEN, E. Magnetic Czochralski silicon as detector material. Nucl. Instr. and Meth. Section A, v. 579, p. 648-652, 2007.

9. FRETWURST, E.; LINDSTRÖM, G.; STAHL, J.; PINTILIE, I.; LI, Z.; KIERSTEAD, J.; VERBITSKAYA, E.; RÖDER, R. Bulk damage effects in standard and oxygen-enriched silicon detectors induced by ${ }^{60}$ Co-gamma radiation. Nucl. Instr. and Meth. Section A, v. 514, p. 1-8, 2003.

10. HÄRKÖNEN, J.; TUOMINEN, E.; TUOVINEN, E.; LASSILA-PERINI, K.; MEHTÄLÄ, P.; NUMMELA, S.; NYSTEN, J.; HEIKKILÄ, P.; OVCHINNIKOV, V.; PALOKANGAS, M.; 
YLI-KOSKI, M.; PALMU, L., KALLIJÄRVI, S.; ALANKO, T.; LAITINEN, P.; PIROJENKO, A.; RIIHIMÄKI, I.; TIOURINE, G.; VIRTANEN, A. The Effect of Oxygenation on the Radiation Hardness of Silicon Studied by Surface Photovoltage Method. IEEE Trans. Nuclear Science, v. 49, n. 6, p. 2910-2913, 2002.

11. CAMARGO, F. Development of Dosimeters with Rad-Hard Silicon Diodes for High Dose Dosimetry. PhD Thesis, USP, São Paulo, 2009. 